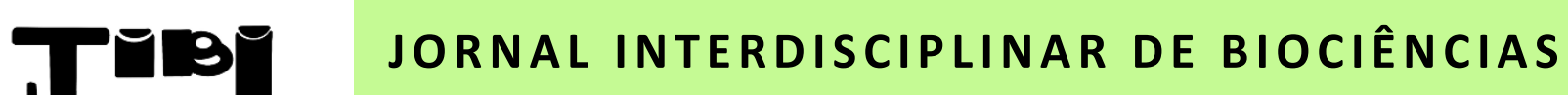

Homepage: http://www.ojs.ufpi.br/index.php/jibi

\section{Análise histológica de traqueia e pulmão de neonatos caninos}

\section{Histological analysis of trachea and lung of newborn dogs}

Andrezza Braga Soares da Silva ${ }^{1 *}$, Maria Michele Araújo de Sousa Cavalcante ${ }^{1}$, Victor Jampierre da Silva Barros ${ }^{1}$, Heliana de Barros Fernandes ${ }^{1}$, Luana de Oliveira Lopes ${ }^{1}$, Eunice Anita de Moura Fortes $^{1}$, Maíra Soares Ferraz ${ }^{1}$, Márcia dos Santos Rizzo ${ }^{1}$, Aírton Mendes Conde Junior ${ }^{1}$

${ }^{1}$ Departamento de Morfologia, Centro de Ciências da Saúde, Universidade Federal do Piauí

\begin{abstract}
A B S T R A C T
The neonatology science is, in Veterinary Medicine, studying the post-birth to the development of certain characteristics of resistance, which for canines occurs until the second week of life. The newborn requires a precise approach given the particularities of their physiology and immunology extremely immature. The histological study elucidates problems morphological and functional abnormalities, as it provides a reliable and microscopic analysis. Aimed to analyze trachea and lung of newborn dogs through techniques of basic histology. We used five neonates that died postpartum. These were weighed, measured and dissected. Proceeded to the extraction of the trachea, bronchus and lung for submitting these samples to histological routine. The tracheal tissue presents a pseudostratified columnar ciliated epithelium with globet cells, a small amount of glands in the lamina propria and hyaline cartilage not fully developed. As regards the bronchial tissue may be observed well defined layers, pulmonary pseudostratified columnar ciliated epithelium with goblet cells in the lamina propria several bundles of smooth muscle and thick vascularized tissue. Likewise, the signs of bronchial cartilage present under development. The bronchioles also feature the common pulmonary epithelium and lamina propria also normal pens without smooth muscle. The bags alveolar lung cells showed typical. The lung tissues of newborn dogs present is still in development stage. It is possible to understand patterns of histogenesis and morphogenesis in newborn dogs.
\end{abstract}

KEYWORDS

Newborn dogs; Histology; Respiratory system

RESUM O

A neonatologia é a ciência, dentro da Medicina Veterinária, que estuda o período pós-nascimento até o desenvolvimento de certas características de resistência, que para os caninos se dá até a segunda semana de vida. O neonato exige uma abordagem precisa dada às particularidades de sua fisiologia e imunologia extremamente imaturas. O estudo histológico elucida problemas de anormalidade funcional e morfológica, na medida em que proporciona uma análise microscópica fidedigna. Objetivou-se analisar traqueia e pulmão de neonatos caninos por meio de técnicas de histologia básica. Foram utilizados cinco neonatos, que vieram a óbito pós-parto. Estes foram pesados, medidos e posteriormente dissecados. Procedeu-se a extração da traqueia, brônquios e do pulmão para a submissão destas amostras à rotina histológica. $\mathrm{O}$ tecido traqueal apresenta um epitélio colunar pseudoestratificado ciliado com células caliciformes, pouca quantidade de glândulas na lâmina própria e cartilagem hialina não completamente desenvolvida. Quanto ao tecido dos brônquios, podem-se observar as camadas bem definidas, epitélio colunar pseudoestratificado ciliado com células caliciformes, lâmina própria com vários feixes de músculo liso e espessa camada de tecido conjuntivo vascularizado. Da mesma forma, as placas de cartilagem nos brônquios apresentam-se em desenvolvimento. Os bronquíolos também apresentam o epitélio do tipo respiratório e lâmina própria também normal, cercados sem músculo liso. Os sacos alveolares apresentaram células pulmonares típicas. Os tecidos pulmonares de neonatos caninos apresentam-se ainda em estágio de desenvolvimento. O estudo morfológico do pulmão e traqueia de neonatos caninos é capaz de esclarecer padrões de histogênese e morfogênese nos mesmos.

PA L A VRAS - CHAVE

Neonatos caninos; Histologia; Sistema respiratório 


\section{INTRODUÇÃO}

A neonatologia é a ciência que está relacionada ao estudo do período neonatal compreendendo desde a fase pós-natal até o desenvolvimento de algumas características de resistência (PASSOS, 2006). De fato, os recémnascidos, em especial o filhote canino, é um paciente diferenciado e que apresenta um metabolismo em desenvolvimento (LÚCIO, 2008). Em cães, este período é caracterizado por uma elevada mortalidade neonatal (cerca de 20 a 30\%), em decorrência de várias razões (INDREBO et al., 2007).

No período neonatal ocorrem diversas alterações, que podem afetar o correto desenvolvimento e o bem-estar animal. Verificam-se, entre outras, a hipóxia por alterações na circulação uteroplacentária, que acarreta sérios problemas pulmonares e distúrbios do cordão umbilical durante a gestação, além de distocias e contrações uterinas intensas (LÚCIO, 2008). Uma vez observados tais problemas, é de suma importância a preparação e os cuidados especiais com estes animais, de modo a estabelecer uma melhora na qualidade de vida do recémnascido canino.

O sistema respiratório é a primeira região interna do corpo que entra em contato com o meio externo. Para recém-nascidos este é um dos sistemas mais vulneráveis (SILVA, 2008). Durante a respiração, inúmeras partículas e substâncias químicas são depositadas no aparelho respiratório, primeiramente nas vias aéreas, uma interface entre o meio interno e os microrganismos, alérgenos ou partículas inaladas. Segundo estudos, o sistema respiratório está em desenvolvimento em recém nascidos de algumas espécies de mamíferos (KRAUSE e LEESON, 2005).

$\mathrm{Na}$ mucosa respiratória, o transporte mucociliar desempenha um importante mecanismo de defesa (BLANCO et al., 2009). A eficiência desse transporte depende de fatores como a espessura da camada do muco, composição e propriedades reológicas do muco, além de cílios em células com estrutura perfeitamente preservada a fim de desempenhar com eficiência a sua movimentação.

A falência ou imaturidade do sistema ciliado, porém, pode deteriorar a qualidade de vida do indivíduo desencadeando múltiplas implicações: facilitação de colonização por bactérias, aumentando o risco de infecções respiratórias, e o aumento de contato entre agentes nocivos e o epitélio respiratório (BLANCO et al., 2009). O estudo desta área do corpo possibilita um melhor manejo do animal e a previsão de complicações decorrentes da imaturidade de alguns sistemas. Desta forma é imprescindível estabelecer padrões de normalidade, que permitam aos médicos veterinários traçar medidas prognósticas adequadas.
Para formular planos diagnósticos e tratamento para patologias neonatais, é preciso conhecer os aspectos que diferenciam os recém-nascidos dos adultos. Vários estudos têm demonstrado que há diferenças significativas entre o animal adulto e o recém-nascido como, por exemplo, rins e fígado imaturos (DOMINGOS et al., 2008). Diferenças nas funções de termorregulação, cardiopulmonar e gastrintestinal também podem ser observadas entre os filhotes e os adultos (CARDOSO, 2000).

Neste trabalho foi discutido a hipótese de que parte do sistema respiratório continua em desenvolvimento após o nascimento e desta forma necessita de cuidados especiais. Para tanto, objetivou-se analisar a histologia da traqueia, pulmão, brônquios, bronquíolos para estabelecer um padrão de referência em neonatos caninos tardios, bem como os estágios de desenvolvimento tecidual do sistema respiratório destes animais.

\section{MATERIAL E MÉTODOS}

Foram utilizados cinco neonatos caninos vindos a óbito e obtidos por doação do Hospital Veterinário da Universidade Federal do Piauí, no Centro de Ciências da Saúde. Os animais foram encaminhados ao Laboratório de Histologia e Embriologia, onde foi realizado o procedimento de extração dos órgãos visualizado na figura $\underline{1}$.

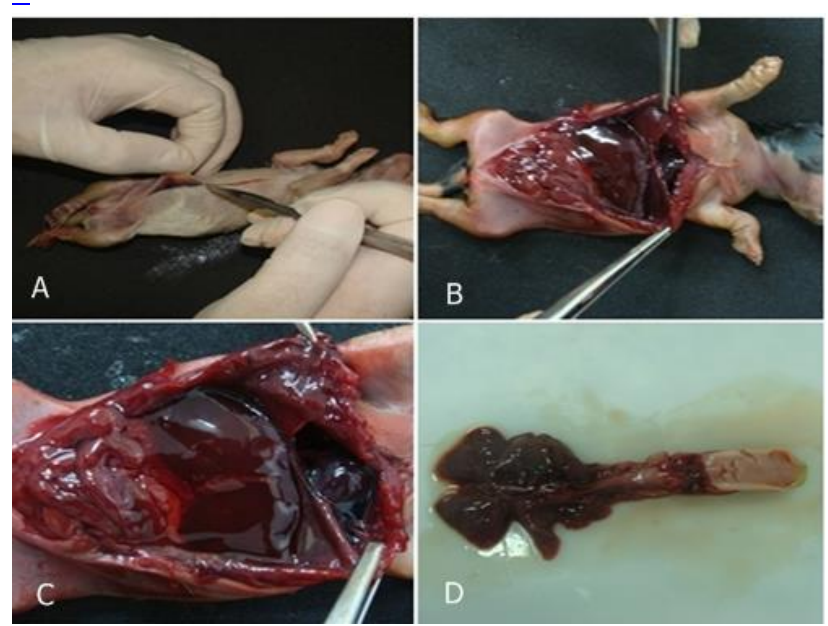

FIGURA 1: A, B, C: fotografia do processo de extração dos órgãos. D: Trato respiratório extraído de neonato canino.

Subsequentemente, os órgãos foram imediatamente conservados em solução de formaldeído a $10 \%$ pelo período de 48 horas. Posteriormente, foram submetidos a processamento e coloração histológicos de rotina, método de hematoxilina-eosina e Tricrômio de Masson realizando-se em seguida a confecção de lâminas para exame por microscópio de luz, segundo protocolos específicos para inclusão em parafina e historresina (JUNQUEIRA, 2013). 


\section{RESULTADOS E DISCUSSÃO}

Em neonatos, o tecido traqueal apresenta epitélio colunar pseudoestratificado ciliado com a presença de grande quantidade de células caliciformes (Figura 2.a). Tais células são necessárias à produção de muco, que permite a proteção do epitélio pulmonar (GARTNER, 2007).

Abaixo do epitélio há uma lâmina própria composta por um tecido conjuntivo frouxo, rico em fibras elásticas (Figura 2.a). Porém não é observada a intensa presença de glândulas serosas, comum em animais adultos. Tais glândulas estão geralmente localizadas próximas às junções dos anéis cartilaginosos. A baixa quantidade de glândulas pode estar relacionada com o desenvolvimento incompleto no neonato canino (SILVA, 2008). No estômago, as glândulas são formadas a partir da invaginação do epitélio (GETTY, 1986). A traqueia de neonato apresenta estas glândulas aparentemente derivadas do epitélio (Figura 2.a).

A região entre os anéis cartilaginosos é composta por um tecido conjuntivo denso, onde se observa grande quantidade de fibras colágenas (Figura 2.b). Esta região também se apresenta bastante irrigada por vasos sanguíneos. Uma vez que as cartilagens são desprovidas de capilares e necessitam de um aparato de oxigenação eficiente que promova o suprimento das necessidades respiratórias das células envolvidas, é de extrema importância a irrigação adequada nesta região (JUNQUEIRA, 2013).

Logo abaixo da lâmina própria observa-se a presença dos anéis de cartilagem hialina, todos envoltos pelo pericôndrio (Figura 2.e). De fato, a cartilagem hialina ainda não está bem desenvolvida, uma vez que existe uma grande quantidade de matriz cartilaginosa. Esta intensa produção de matriz é típica do amadurecimento da cartilagem nos animais. (JUNQUEIRA, 2013).

Em seguida, existe uma camada densa e contínua de músculo liso (Figura 2.f), que parece envolver a traqueia. Diferente do que ocorre nos brônquios, onde se localiza próxima ao epitélio, de músculo liso (Figura 2.f), que parece envolver a traqueia. Diferente do que ocorre nos brônquios, onde se localiza próxima ao epitélio, a camada de músculo liso está disposta entre a cartilagem e a camada

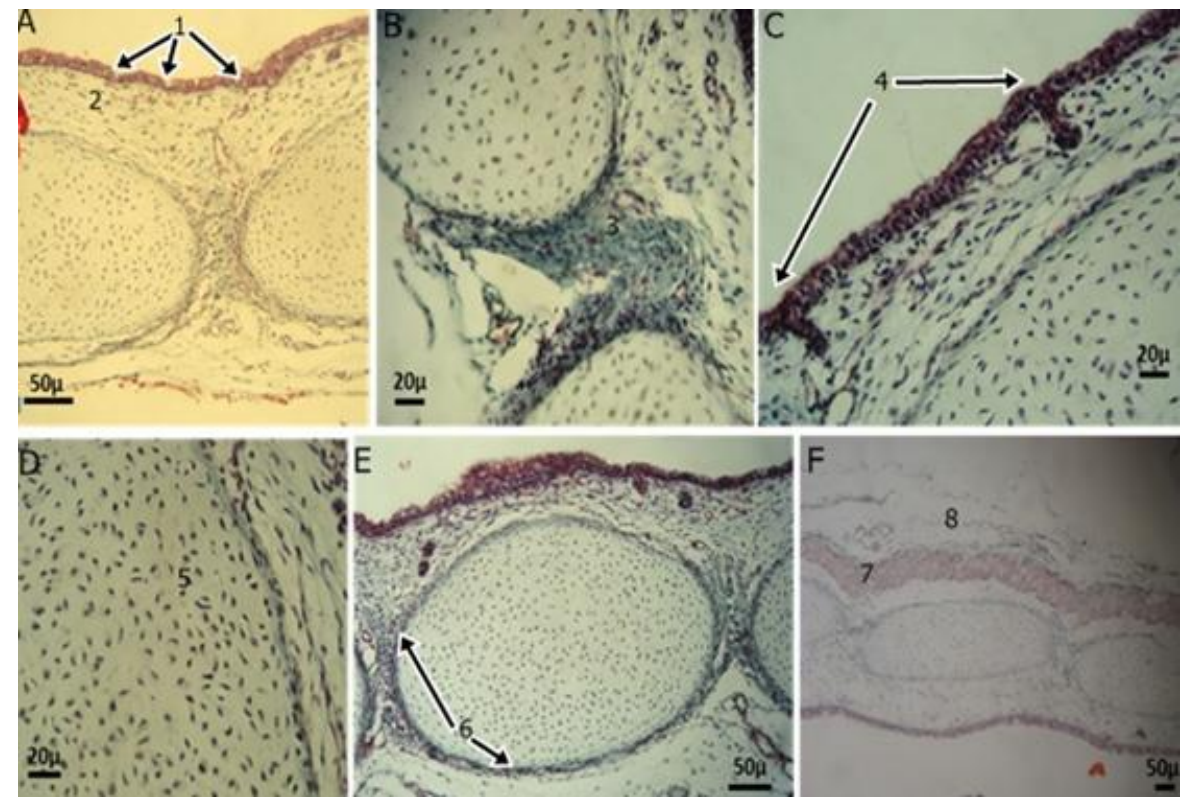

FIGURA 2. Fotomicrografias de traqueia de neonato canino. A - em (1) epitélio colunar pseudoestratificado ciliado com células caliciformes e (2) tecido conjuntivo frouxo; B (3) fibras colágenas (tecido conjuntivo denso); C (4) histogênese glandular; D (5) cartilagem; E (6) pericôndrio e F (7) músculo liso e (8) serosa.

adventícia que a envolve. Tal fato fornece um mecanismo de contração do lúmen traqueal que permite a tosse e, consequentemente, a expulsão de material estranho da traqueia. (JUNQUEIRA, 2013). Também foi observada a camada adventícia que envolve a traqueia sendo formada por tecido conjuntivo frouxo.

$\mathrm{Na}$ análise dos pulmões de neonato canino observou-se por meio de um corte transversal que os brônquios apresentaram todas as suas camadas bem definidas. Além disso, foi visualizado o epitélio contendo vilosidades e que consiste de células ciliadas e células prismáticas secretoras de muco, as células caliciformes (Figura 3.a).

Adjacente ao epitélio, observou-se a lâmina própria. No pulmão, a lâmina própria do epitélio vem seguida por vários feixes descontínuos de músculo liso e 
uma espessa camada de tecido conjuntivo, contendo algumas peças de cartilagem em desenvolvimento, podendo ser observados ricos núcleos com pouca matriz extracelular, e glândulas serosas e mucosas (Figura 3.b e 3.c). A lâmina própria encontrada é semelhante à descrita por Gartner (2010), apresentando-se delgada e circundada pelo músculo liso, o qual se dispõe ao redor do lúmen.

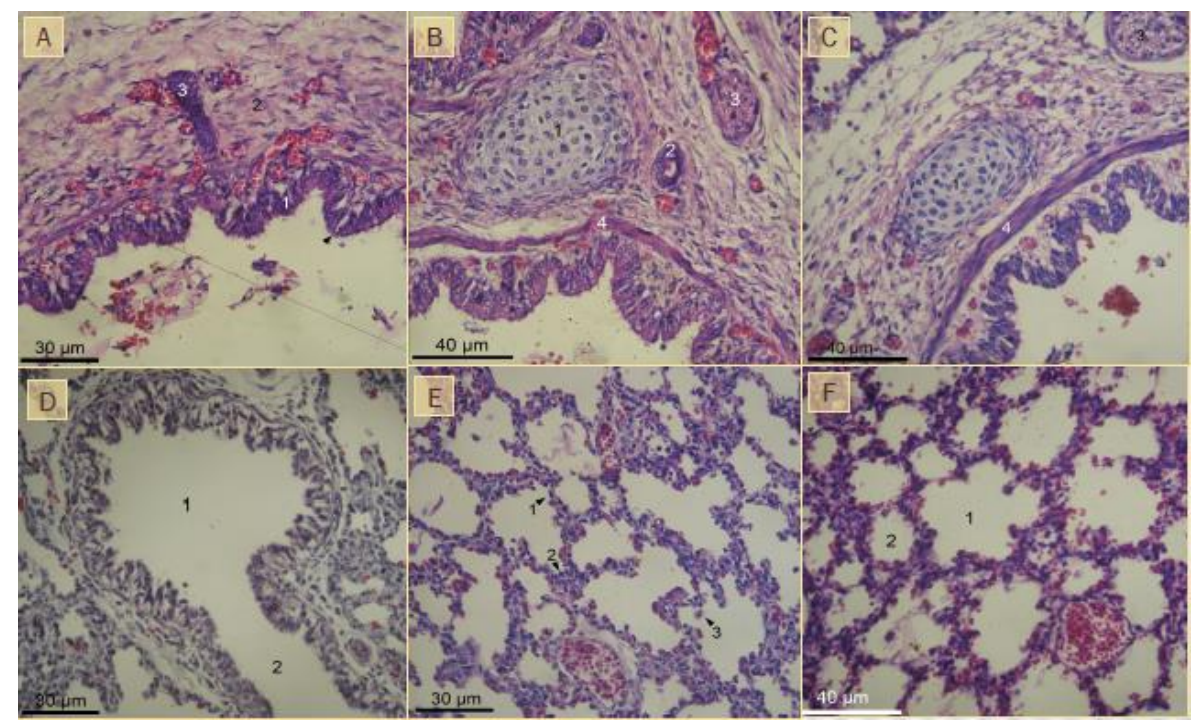

FIGURA 3. Fotomicrografia de pulmão de neonato canino. A - brônquios, nota-se em (1) o epitélio colunar pseudoestratificado ciliado com células caliciformes, $(\boldsymbol{\Lambda})$ vilosidades com células prismáticas ciliadas e células caliciformes, (2) tecido conjuntivo e (3) glândulas serosas. B e C - brônquios, vê-se em (1) peça cartilaginosa em desenvolvimento, (2) glândula serosa, (3) glândula mucosa e (4) músculo liso. D - bronquíolos, em (1) bronquíolo terminal e em (2) bronquíolo respiratório. E e F - sacos alveolares e alvéolos. Em E observamse (1) pneumócitos tipo I, (2) pneumócitos do tipo II e (3) macrófagos alveolares. F (1) sacos alveolares e (2) alvéolos.

As secções transversais dos bronquíolos revelaram um epitélio simples com vilosidades constituídos por células colunares e células ciliadas caliciformes espaçadas, seguido da lâmina associada com uma camada de tecido conjuntivo. Ao comparar a espessura das paredes dos brônquios com a dos bronquíolos, é possível notar que a musculatura dos bronquíolos é relativamente mais desenvolvida que a musculatura brônquica (Figura 3.d).

As secções longitudinais dos bronquíolos mostraram sua estrutura ramificada com bronquíolos respiratórios cercados por músculo liso bastante evidente e epitélio sem vilosidades que se ramifica em bronquíolos terminais, representados por tubos curtos cercados por músculo liso, fluindo em ductos alveolares, que não apresentam formato definido, associando aos sacos alveolares de forma arredondada, que consistem em grupos de alvéolos aglomerados ao redor de um espaço aéreo comum (Figura 3.d). De acordo com Gartner (2010) ao contrário dos bronquíolos respiratórios, os ductos alveolares não possuem uma parede própria, podendo estabelecer uma possível relação do formato indefinido dos ductos alveolares.

Os sacos alveolares que conectam os alvéolos pulmonares mostraram células pulmonares típicas: na maioria deles foi encontrada pneumócitos tipo I, que reveste as células endoteliais, apresentando forma alongada, ricos em citoplasma e com núcleos achatados; pneumócitos tipo II, com forma cúbica e esférica e núcleo central. Foi possível observar ainda, uma alta frequência de macrófagos alveolares no interior dos alvéolos (Figura 3.e e 3.f). Segundo Junqueira (2013) os pneumócitos tipo I, têm núcleo achatado fazendo saliência para o interior do alvéolo. Essas células em neonatos apresentaram-se alongadas e devido a extensão do citoplasma, os núcleos encontram-se distanciados uns dos outros.

A traqueia e os pulmões de neonatos caninos apresentam sinais de imaturidade tecidual, representados principalmente pelo desenvolvimento incompleto da cartilagem em diversos pontos. Os tecidos mesmo próximos entre si, podem apresentar estágios diferentes de desenvolvimento epitélio colunar pseudoestratificado ciliado.

\section{CONCLUSÃO}

Estudar a morfologia normal dos tecidos animais servem como base para pesquisadores e médicos veterinários reconhecerem tecidos alterados e estabelecerem medidas prognósticas de tratamento para possíveis alterações neonatais. Tais resultados podem servir como base para outros trabalhos como análise moleculares, identificação de células por imuno- 
histoquímica, vias bioquímicas de desenvolvimento celular e histogênese.

\section{REFERÊNCIAS}

BLANCO, E. E. A. et al. Efeito do óxido nítrico no transporte mucociliar. Braz. J. Otorhinolaryngol. v. 6, n. 1, p. 876-871, 2009.

DOMINGOS et al. Cuidados básicos com a gestante e o neonato canino e felino. Jornal Brasileiro de Ciência Animal. v.1, n.2 , p. 94-120, 2008.

GARTNER, L. P e HIATT, J. L. Atlas colorido de histologia. 5. ed. Rio de Janeiro: Guanabara Koogan, 2010.

GETTY, R. Sisson e Grossman anatomia de animais domésticos. 5. ed. vol. 2. Rio de Janeiro: Guanabara Koogan, 1986.

INDREBO, A; TRANGERUD, C; MOE, L. Canine neonatal mortality in four large breeds. Acta Veterinaria Scandinavica. v.49, p1-2, 2007.

JUNQUEIRA, L. C. e CARNEIRO, J. Histologia básica. 10. ed. Rio de Janeiro: Guanabara Koogan, 2004.

KRAUSE, W. J; LEESON, C. R. The postnatal development of the respiratory system of the opossum. I. Light and scanning electron microscopy. Developmental Dynamics, v. 137, n. 3, p. 337- 335, 1973.

LÚCIO, C. F. Influência das condições obstétricas ao nascimento sobre padrões de vitalidade e bioquímica neonatal na espécie canina. São Paulo: 2008. 76 f. Dissertação (Mestrado em Reprodução Animal) Faculdade de Medicina Veterinária e Zootecnia, Universidade de São Paulo, São Paulo, 2008.

PASSOS, J. F; Neonatologia Veterinária. Trabalho de conclusão do curso de medicina veterinária. 2006. $55 f$ (Monografia) - Área de obstetrícia veterinária. União Pioneira de Integração Social, Brasília, 2006. 